\title{
AUTOMATION OF INDUSTRIAL PROCESSES AND ITS IMPACT ON THE LABOR MARKET AND EDUCATION. SELECTED ASPECTS
}

\author{
Ryszard MARSZOWSKI ${ }^{1 *}$, Leszek DROBEK ${ }^{2}$ \\ ${ }^{1}$ Central Mining Institute, Katowice; rmarszowski@ gig.eu, ORCID: 000000022855-7121 \\ ${ }^{2}$ Central Mining Institute, Katowice; Idrobek@ gig.eu, ORCID: 0000-0003-2114-089X \\ * Correspondence author
}

Purpose: the main purpose of the article is to justify need for interdisciplinary professional training of employees for challenges related to the growing importance of dynamically developing automation, which is closely related to the pace of civilization development.

Design/methodology/approach: the theses presented in the article have been verified using: literature review, critical literature analysis, document research and comparative analysis.

Findings: based on content of this article, a future emerges in which man, industry and surrounding reality will be shaped by automation developing with a hitherto unknown dynamics. This phenomenon may lead to the disappearance of a world dominated by the industrial age and the transition to a new era determined by technologies, dominated by data flow and its analysis. In automated economies, knowledge that is exemplified by the knowledge society that creates innovative solutions has become a key capital. It seems that automation in the context of economies' competitiveness will determine the need to raise the level of education and of competences, and to create and control new knowledge.

Originality/value: the article enriches knowledge and develops discussion in the area of dynamically developing automation. Thanks to the knowledge presented in the article, it can be concluded that the decisive role in creating the development of labor market and education can be overcome by breaking social and professional barriers to automation processes - which may favor the social dimension of the individual and strengthen the sense of human life fullness.

Keywords: human, labor market, education, automation.

Category of the paper: Conceptual paper ${ }^{1}$.

\footnotetext{
${ }^{1}$ The article is the result of research carried out by the Central Mining Institute on behalf of the "KADRA" Trade Union Agreement and the Trade Union Forum as part of the project entitled "A competent trade unionist - how to support employees in labor change processes" co-financed by the European Social Fund under the Operational Program Knowledge Education Development 2014-2020.
} 


\section{Introduction}

As researchers from the field of artificial intelligence at the Universities of Oxford and Yale point out, machines will outperform people in all aspects of intelligence within 45 years, and within 120 years, all the work that man will do will be automated (Robots take over work, 2019). In this light, it is worth asking the question whether automation will solve all existential problems in the future, and man will devote himself exclusively to consumption and pleasure. Will it lead to a global catastrophe in which machines take over the world, becoming ubiquitous, self-learning, which will ultimately lead them to turn against man? Certainly this question cannot be answered in the text below. Rather, it is an attempt to provoke reflection and discussion on the impact of industrial process automation on the labor market and education. From this perspective, it is worth noting that the phenomena and processes related to automation cause transformations within economic organizations and other institutions. Many of them are directly or indirectly related to the areas of employment, human resource management and education. As noted in numerous works, automation as one of the key global changes results in the process of adaptation of labor markets, education systems, institutions and enterprises in the areas of operating principles, information methods and organizational models to build sensitive solutions based on innovations that shape modern (intelligent) enterprises of the future (Borkowska et al., 1988, p. 33). In view of the directions of changes outlined for intelligent and innovative organizations, the special challenge is the need to anticipate the future, improve ourselves in the face of a changing environment, build solutions that respond to changes that may occur in the future, and improve our competitiveness (Kubik, 2012, p. 36).

\section{Automation and knowledge management}

According to the source, the Encyclopedia of Management, automation can be defined in two ways. In the first approach, automation is a term derived from the Greek language from the word automatos, i.e. automatic, which means the process of relieving or completely limiting human physical and mental work using machines and devices that perform repetitive tasks automatically. M. Pawlak holds that this process is possible only "with the use of modern solutions in the broadly defined field of industrial automation, which is constantly developing" (Pawlak, 2007, p. 1). In another approach, automation is perceived as an industrial process where all possible operations that are performed, is transformed from a manual process, to an automated or mechanized one (Gupta, 2007, p. 1). Regarding the development of the phenomenon, it is worth noting that automation developed on a large scale in the United States after World War I - mainly in the fields of chemical technology and the transmission of 
electricity. The first automatic production line started operating in the US in 1923. After World War II, another leap in the level of industrial automation followed - in the 1950s, numerically controlled machine tools began to be used; in the 1970s, industrial and automated robots warehouses, and in the eighties, completely automated production lines were built. Modern systems engineers do not cease in their search for better solutions, and each day they surprise us with their ideas. Supported by scientists from other fields: electronics, nanoelectronics, chemists, biologists, mechanics, they create new devices and develop new scientific fields: robotics, mechatronics, bionics, and domotics. Japanese and Americans are the driving force (Kaczmarczyk, 2018, pp. 27-28).

The described development of automation implies numerous effects and new phenomena. According to the consulting company McKinsey, in 2025, automation of work requiring knowledge and advanced robotics will be worth 7-11 trillion dollars globally. In turn, the consulting company KPMG and Society of Motor Manufacturers and Traders (UK Association of Automotive Entrepreneurs) estimates that in the United Kingdom by 2030, the value of the connected and autonomous vehicles sector will reach $£ 51$ billion a year. This is, among others, the result of the policy of the British government, which allocates significant financial resources to the development of specialist knowledge about robots and autonomous systems, such as learning machines, unmanned systems, including autonomous vehicles, robots intended for use in hazardous environments, e.g. in space. The thesis suggests that the software and robots that can completely replace human workers by performing duties that are dangerous or unprofitable for humans, can also be used to increase work efficiency.

In light of the indicated processes, trends and forecasts in numerous scientific studies, as well as practical experience, it is clear that today it is recognized that the key capital of the organization is knowledge and its skills, primarily the ability to respond to changes in the environment. Bartlett and Ghoshal even state that:

in today's highly competitive, driven by new technologies (including automation) world with its unique potential, that which is a key barrier to development and achieving strategic goals of companies and organizations is not specialized and is responding to the changing environment of knowledge and experience and potential in the area of organization and management, which creates the basis for their use in achieving the goals and mission of the enterprise (Barlett et al. 1989, pp. 87-94; Barlett 1989).

In turn, Naisbitt claims that while the traditional understanding of the strategic resource capital was material in terms of material, i.e. traditional factors of production, the current formula of this resource exposes three elements: information, knowledge and creativity, along with automation industrial processes (Naisbitt et al. 1985). On the other hand, in the Responsible Development Strategy, which sets the direction of Poland's development, by 2020 , with a perspective until 2030, it is noted that responsible and sustainable development shapes the strength of the national economy and guarantees the growth of innovation. Herein, accordingly, sustainable development of the national economy supported by 
innovations, including automation, forms the foundation for capital that young people can multiply. A huge importance in these processes is attributed to human innovation, as this will determine the strength of the national economy, which will result from the situation on the labor market shaping the purchasing power of the Polish zloty, thereby shaping Poland's position on competitive global markets (Responsible Development Strategy..., 2017). Nonaki (1991), however, perceives these phenomena differently, as he believes that the key source of competitive advantage both in the labor market and in enterprise, is knowledge and the dynamically developing process of automation of numerous spheres of human life associated with it. In his opinion, the changing economic situation shaping the situation in the markets, fueled by dynamically changing and emerging innovative technologies and growing competition can result in the disappearance of products in one day. Enterprises can be successful in such conditions if they are organizations operating on the basis of updating and developing their knowledge, including in this, all related processes, and on this basis, they strive to create new technologies and products. Such actions are defined as markets, including knowledge-based enterprises whose sole purpose is systematic innovation (Nonaka, 1991).

Referring to the above conditions and regularities, knowledge can be ordered according to the following questions: know - what (know what), know - why (know why), know how (know how), know - who (know who) (Knowledge management..., 2000 , p. 13). At present, in the phase of changing global conditions related primarily to automation, commonly known development determinants are disappearing as a result of their lack of efficiency in the development of the company and organization, and in the increase of their competitiveness. This phenomenon is directly related to the process of departing from traditional labor-intensive professions, in favor of smart and innovative professions using IT knowledge. Thus, intellectual capital (Edvinsson et al. 2017, p. 17) and IT competences that allow to beat competition in a globalized computerized and automated world (Szczepanik et al. 2007, p. 12) become the source of economic and market development and the economic success of the enterprise.

Boreham states that companies and organizations with strategic solutions in the field of management are characterized by:

- accepting the benefits of better use of knowledge,

- recognition of the dominant role in knowledge-based organization and management of new professions such as librarians and knowledge management project managers,

- implementation in the enterprise of knowledge-subordinated activities and programs aimed at its more effective use,

- treating information and communication technologies as a tool,

- using appropriate personnel management strategies, i.e. ones that are based on creating an organizational culture in which knowledge is the key value. 
He views Ruggles's notion of knowledge management differently. Boreham believes that knowledge management is an approach that exposes the addition or creation of value through a more active support of know-how, experience and decisions existing within the organization, and in many cases - beyond (Boreham, 1999, pp. 1-2). On the one hand, the examples cited confirm Boreham's observation that the term 'knowledge management' is blurred. On the other hand, they indicate that the term 'knowledge' can also be defined differently.

One of the currents of discussion in management sciences is the shape of the labor market and enterprises of the future in the phase of the Industrial Revolution 4.0. - of which an important element is the industrial automation process. For example, Handy claims that in the near future, over $70 \%$ of all jobs in enterprises will be related with knowledge and will be subject to the process of automation, not physical work. In contrast, Drucker believes that in 20 years time, a typical large enterprise will resemble knowledge-based hospitals or symphony orchestras more than the production facilities known today. The future, therefore, belongs to enterprises whose strategic resource corresponds to the formula: information + knowledge + creativity. Such enterprises, or more broadly 'social systems', propose to call enterprises 'intelligent systems'. However, according to Simon, enterprise intelligence is very difficult to measure and even more difficult to manage. Combating enterprise self-destruction along with the passage of time is already a common managerial task. So let us remember the words of Matsushita, a Japanese connoisseur of management science, in whose opinion in a globalized, internationalized and automated economy, it is necessary to optimally extract every bit of intelligence out of each employee (Simon, 1995).

The new formula for the organization's strategic resource (system), however, means much more than just using existing knowledge. It will also cover its production and sales. In this understanding of the problem of knowledge in an enterprise, often discussed in terms of core competences and core business, an intelligent enterprise is one that produces and purchases 'knowledge', uses it and sells it on, realizing value added. According to what has been said, the essence of an intelligent enterprise, based on automated processes, is determined by the extent to which the enterprise (system) bases its activity on a new strategic resource, and to what extent this new resource is applied in the innovative processes (creation, purchase of new knowledge, use and sale).

The presented approach refers to P. Drucker's proposal of understanding the essence of innovation. For him: "Systematic innovation is the deliberate and organized search for change and the systematic analysis of opportunities for social or economic innovation that such change could enable" (Drucker, 1993). The quoted methodological proposal may also be useful for redefining human resource management in organizations. 


\section{Automation and the labor market and education}

Contrary to the past, the role and significance of employees' professional preparation is currently growing, and is closely related to the rate of civilizational progress, including the extremely dynamically developing automation of the numerous industrial and non-industrial areas mentioned several times. In this light, it seems appropriate to focus on providing staff with the capacity to use new technologies and building innovative behavior. It seems that the modern education model should be subordinated to these goals. This applies not only to the high level of preparation of an adequate number of scientists, innovators and technical staff, but also to the extension of compulsory and vocational training. Such perceptions are found in numerous European Union programming documents in which education in a globalized and an increasingly automated world is recognized as a priority. The European Union recognizes that education (education and training) is necessary for the development of a modern society and a knowledge-based economy. The inclusion of training in the education framework means that it is understood broadly - it is not limited to education in schools and universities, but encompasses all forms of educational activities outside education systems, including, in particular, activities for the improvement of professional qualifications and for broadening participation in culture and civil society (http://ec.europa..., 2019).

The situation on the labor markets and the phenomenon of unemployment significantly determine the changes taking place in educational models of different countries. First of all, strategic actions are aimed at minimizing qualitative structural stratifications, which is associated with a more effective transition of human resources from education to employment. However, the indicated activities and goals are associated with many difficulties, in particular those relating to curricula being developed, which unfortunately cannot fully balance two opposing goals, i.e. preparing young people for the professions that currently exist, and developing in them the ability to adapt in the future to the work they still have due to numerous changes - includeng provoking the progressive automation of numerous processes and functions conditioning the development of humanity that we cannot even imagine.

As the authors of the Foresight report of the staff of the modern economy note, the phenomenon of extremely dynamic changes taking place in the globalized and automated economy implies the need for continuous forecasting and focusing of actions on strategic solutions. Due to this type of perception of the surrounding reality, competitive advantages are formed by way of the ordered and methodologically shaped concentration of possessed potentials in the most developmental spaces. The European Union now recognizes the important need for long-term forecasting. The indicated need results from the enormous dynamics of changes, both quantitative and qualitative, shaping the position of labor resources in the macro and micro economic dimensions. 
The lack of scientifically documented and methodologically shaped knowledge forecasting economic phenomena, including future staffing needs reported by employers, determines numerous errors in the development of strategic programs of activities and weakens competitive advantages - and may lead to deepening of structural stratifications in labor markets. As has already been noted several times, the national economy in its development should be based on innovation and automation and strive to create new and unique technologies and the information society (Lewandowski, 2018, pp. 1-11). It is worth noting in this context that the number of robots per one industrial worker in Poland has increased tenfold over the past decade. Despite this, we are still far behind in terms of robotization. Poland still has a lot to catch up on compared to Europe. Although the number of robots per employee increased ten times compared to 2006 , it is only 37 percent. number of robots per employee employed in industry in the EU15. In turn, analyzes and research clearly indicate that the highly developed human capital will be decisive for the indicated direction of development.

In a globalized world, education is a key factor in the development of human capital. It is through educating the society that members of that society get richer, create competitive advantages and skillfully develop their economies towards information policy. It seems that the factors shaping the position of the national economy in the EU will primarily come from education systems, especially those related to technical higher education, by determining new and innovative technologies and solutions in the area of IT and related to the phenomenon of automation.

As numerous analyses and studies show, in the most developed economies, a very high flexibility of the education system is observed, thanks to which it can react very quickly to changes taking place in the environment and to adapt to them. The indicated flexibility shapes the relations between education and the labor market very favorably in the end, implying that easy access to the best educated and professionally developed qualified staff creates strength and innovation in the automated economy (Matusiak et al. 2009, pp. 7-8). It is worth noting here that the automation process determines numerous threats in the sphere of the labor market and education, for which the EU recommends establishing high-quality, flexible and inclusive vocational education and training systems, as well as an appropriate social security system aimed at moving the workers that are replaced by machines, to other industries. The already observed exchange of employees for machines has an impact, among others on the loss of creativity, innovation and motivation of other employee groups. In this light, the future labor market will require high adaptation and adaptation skills from the employee. It seems that men with lower education and lack of technical skills are most at risk of being replaced by machines by the group.

In the context of the described changes, it is extremely interesting to anticipate the process of growth and development of the digital society in the automated world (Understanding the Union's policy..., 2014). In this society, the so-called class of digital employees can work anywhere and create numerous personal and business digital contacts. In this way, this class 
determines the process in which digital knowledge becomes the foundation of the power of the global automated economy. In such a shaped world, digital creativity and curiosity prevail and these are the characteristics that mainly characterize young people. The need to exchange knowledge between young people and the older generation is clearly emerging in this process. The indicated relationship aims at the urgent need to reduce the growing intergenerational information gap. It seems that only communities in which the gap will not occur will be able to create new technologies and solutions in a world based on digital knowledge (Building..., 2014, pp. 7-8).

An important aspect in this regard is the maintenance of traditional forms of contact. Everything cannot be based solely on virtual communication. It is important to preserve traditional forms of intergenerational cooperation based on joint decision-making, motivation to cooperate, loyalty, integrity and honesty. In an increasingly digitized world, supporting intergenerational integrity and openness is paramount to digital wisdom (Budnikowski, 2003).

On the canvas of the aforementioned changes and the digital society, the process of using digital technologies to create innovations is developing. They shape and express themselves through the process of convergence between nano-, biological and information technologies, and cognitive sciences (hereinafter NBIC technologies). NBIC technologies are developing extremely dynamically, creating progress in the field of health, energy, environmental protection and production, leading to the transformation of other, even non-technical areas outside the area of their impact. As a result, the convergence process determines integration, openness and comparability, leading to visionary solutions (Cognitive Sciences..., 2014). An equally important effect of convergence is the creation of internal and external cooperation in creating innovations and overcoming mentality barriers towards innovations in order to strengthen their acceptance.

In a different perspective, the future is seen through the prism of such determinants as automation, digitization and related phenomena. These are the determinants in the near future that will most likely lead to a redefinition of work. Currently, the disappearance of full-time employment as a dominant form of employment relationship is being noticed in this area. According to the research results, more than half of all Poles recognize that in the future it will be necessary to work in several professions as a prerequisite for maintaining professional activity within the labor market. In this sphere, digital competence will be the guarantee of professional success. In the area of digital competences, strategic advantages in the labor market will mainly result from the skills of data analysis and related professions of the future such as Data Scientist - a term describing the profession of a person dealing with the analysis of disordered data, in particular big data. This moniker was popularized by the Harvard Business Review in 2012. As the Polish equivalent, the term "data master" is sometimes used (Data Scientist..., 2012). This methodology emphasizes the close cooperation and communication of IT maintenance professionals (administrators) and software development specialists (programmers). Moreover, it takes into account the interdependence of 
IT development and maintenance, and shortens the time of implementing functions in the software. A further term 'DevOp engineer' (development operations engineer) was proposed in 2019 by Damon Edwards, based on the notion of 'DevOps' first coined in 2009 by Patrick Debois during the DevOps days in Ghent (Data Scientist..., 2012).

In the process of changes taking place based on the progressive computerization of societies and economies, it is expected that by 2050 , nearly $1 / 2$ of the current occupations laborwill disappear due to their displacement by the automation process, i.e. as a result by machines. It is forecasted that in the most developed economies, over 50 percent of the total jobs will be automated; for the national economy, it is estimated to be a percentage of 40 percent. In this context, it is worth noting that digital competency in Poland is among the lowest in Europe every fifth Pole has never used the Internet; only $57 \%$ of all Poles use the Internet every day, whereas the average figure for the EU as a whole is $71 \%$. Furthermore, only $39 \%$ of all Poles use a computer at work, while in the EU as a whole the figure is 50\% on average (Italy, 2017).

Information on the future of qualified staff in the age of automation can be found in laborstrategic documents defining the future of given areas and which apply foresight methodology ${ }^{2}$. In this light, extremely valuable are, among others, records derived from the Regional Strategy for the Innovation Development of the Śląskie Voivodship for the years 2013-2020 (RIS gives) (Regional Strategy, 2012). This Strategy is an important document outlining development directions, including that of Upper Silesian Metropolis.

Taking into account the successful development of qualified staff, it is certainly necessary to orient their education in accordance with areas with the greatest potential for technological development in the voivodship. This will be in domains such as: medical technologies, technologies for the energy and mining, technologies for environmental protection, information and telecommunications technologies, production and processing materials, transport and transport infrastructure, machine, automotive, aviation and mining industries, nanotechnologies and nanomaterials (Regional Strategy, 2012).

The preparation of qualified staff at each level of education that can ensure a sustainable stream of labor supply in these areas seems to be a serious challenge in which society together with relevant representatives of the world of education, science and culture should participate adequately to its potential (Marszowski, 2017, pp. 135-141).

\footnotetext{
${ }^{2}$ Foresight is both a research field and a practical enterprise popularized around the world in the last two decades of the 20th century. The goal of foresight research is primarily to identify and assess future events, needs, opportunities and threats related to social and economic development, and to prepare appropriate pre-emptive actions in the field of science and technology. Both the foresight process and its results are used to create and then implement the scientific, technical and innovative policy of the country or region (as well as internationally) and as a tool for developing a culture of thinking about the future in society. Organized nationally or regionally, foresight programs involve representatives of public authorities, industry, NGOs, universities and research organizations as well as wide public circles in an open, focused discussion on the future. The results of public foresight programs inform decision-makers about new development trends, help to agree development scenarios and harmonize the activities of social partners (government, scientific and industrial environments, companies, sectors of the economy) and help determine the criteria for financing science and technology. More: http://www.foresight.pl/, 11.05.2019.
} 
Equally important in this light is the work entitled Foresight of modern economy staff. The need to prepare qualified staff for the upcoming labor market challenges in the following areas is clearly based on this work:

Automation and Robotics:

- construction and civil engineering,

- care services and quality of life,

- business related services,

- tourism and Recreation,

- free time,

- nutrition technology and food industry,

- logistics and transport engineering,

- environmental engineering (devices for environmental protection).

In turn, due to horizontal (prospective) fields, the authors of this study point to:

- IT and internet services,

- biotechnology,

- medicine and health care,

- finance,

- education,

- safety,

- entertainment.

On the level of the above indications and forecasts, there is a precise list of professions that can be considered as future staffing needs of local, regional, voivodship markets and the national labor market. These include, based on anticipation of study content, which are RSI and FKNG, qualified staff in the following professions corresponding to the horizontal field.

In the field of IT and internet services:

- network specialists in the field of IT and internet services,

- IT specialists,

- mechatronics,

- copywriter (person responsible for the text page of the ad; creating its concept and final text),

- master webmaster (a person who designs, creates and maintains a website),

- traffic manager (a person who tracks website traffic),

- met new metrics analyst (dealing with detailed numerical tracking of website movements),

- content manager (dealing with the organization and methods of presenting web content),

- e-mail channel specialist (a person dealing with the development of the company's strategy regarding communication by means of incoming and outgoing mail), 
- ethical hacker (a person dealing with searching for weak points in networks and their protection),

- $\quad$ researcher - information manager,

- broker and information selector,

- specialist in classifying and indexing information / content,

- specialist in information flow management,

- auditor of information reliability,

- specialist in optimizing information positioning in search services,

- intellectual property rights broker.

In the field of biotechnology: bio-farmer, "disinfectant" of the environment, biotechnologist engaged in engineering in plant and animal breeding. In the field of medicine and health protection: hospital manager, health care facilities, care-givers, nurses, rehabilitators, plastic surgeons, cosmetologists, fitness instructors, dietitians. In the field of finance: business specialists, financial analysts, e-bankers, insurers, specialists in interactive and electronic customer service centers, centralized billing systems, designers of financial service packages, handlers of integrated financial products and specialists in the field of electronic promotion channel financial services and distribution channels of financial products, telebanking and tax specialists (including in the fields of real estate, mortgage value and risk of companies, clients in trade). In the field of education: media didactitions, coaches, trainers and director of training programs, computer-assisted education specialists, education brokers, didactic technology experts, teletutors. In the field of security: specialists in biometrics (biometrics allows identification of identities based on unique physical characteristics). In the field of entertainment: multimedia program managers, multicultural managers, social marketing specialists, theme park animators.

In the perspective of the upcoming changes and the related needs for future professions, there are several significant regularities shaping the position of the employee on the labor markets. Research shows that expertise is a factor that $70 \%$ of all employers find attractive. In contrast, soft competences rate at $33 \%$. The situation of the inverse distribution of the percentage share of the factor is revealed during the job loss phase. Success in the 21 st century will be determined by graduates having broad competencelabor and the ability to adapt to changes that will take place through the employment life span, the aforementioned flexibility, motivation for lifelong learning, the ability to manage information and change, holding competence in the field of interpersonal communication and having the ability to work in a team (Matusiak et al. 2009).

The considerations to date have focused on the sphere of labor demand. It should be noted that the changing global economy also has a significant impact on the supply stream. First of all, it creates an area of staffing needs inextricably linked with the qualifications, competences and skills of qualified staff. In the area of socio-professional determinants of human resources 
within the labor market, the changing competency expectations and related skills should be noted. Considering the conditions already mentioned, as a result of the analyzes and research, the following competences will be indispensable labor (National Program, 2013, p. 3):

- interdisciplinary,

- speed of action,

- innovative and adaptive thinking,

- computational thinking,

- intercultural competence.

As it has been noted earlier, the 21 st century is characterized by the disappearance of one-time employment and performing work in one workplace. Simultaneously with this process, narrowly specialized knowledge resources for education that guarantees having future competences, which include (National Program, 2013, p. 3), are losing their significance. What continues to be relevant are:

- ability to work in a team,

- ability to work in information noise,

- virtual cooperation skills,

- ability to communicate in the "real world",

- project work skills.

Against this background, it is assumed that the final success in a globalized labor market will be determined by the ability to learn quickly, and be flexible, mobile and adaptable to the changing environment. Thus, the need to permanently adapt professional qualifications and create new values is an inevitable consequence of the automated society.

\section{Conclusions}

On the canvas of all the content contained in this article, the image of a future clearly emerges in which man, industry and the surrounding reality will be shaped by a process developing with hitherto unknown dynamics - automation. This will lead to the disappearance of the world dominated by the industrial age and will engender a transition to a new era determined by technologies dominated by data flow and analysis. The changes taking place will be focused on selected economic and social areas (Regional Strategy, 2012). As it has already been noted, they will shape the process of convergence between nano-, biological and information technologies, as well as cognitive sciences. These technologies, developing extremely dynamically, create progress in the sphere of the labor market, education, health protection, energy, environmental protection and production and lead to transformation of other, even non-technical areas - outside the area of their impact. In this light, it seems that the 
future of labor markets and education systems will be determined by two currents. In the first of these, labor markets and education systems will be on the margins of change as a result of being excluded from the process of participation in the aforementioned convergence. In contrast, they will remain relevant on the basis of their development potential and will enjoy the resulting benefits on an equal footing with other participants.

It seems that according to the above thesis, education will take on a huge role. This is education as not only a tool for transferring knowledge and skills, but also a key determinant shaping social attitudes and behavior. In this light, processes related to the automation of economies can increasingly determine unexpected stratification and differentiation both in the social and economic spheres. In the pessimistic scenario, their final effect may be marginalization or exclusion of individuals and social groups from profits resulting from the automation process. Knowledge and education fit into this area of adverse effects as factors that can limit and minimize them. Today, in globalized and automated economies determined by key capital, knowledge has regained importance, and is exemplified by the knowledge society creating competitive and innovative solutions. It seems that the automation process in the context of increasing competitiveness of economies will determine the need to permanently raise the level of education and of competences, as well as compel the creation and mastering of new knowledge.

In this light, it seems that the decisive role in creating the development of the labor market lies in education, and education can overcome mentality barriers to automation processes to strengthen its acceptance. As demonstrated by numerous sources cited in the text, the desire to develop automation leads directly to economic growth in the dimension of both the state and local communities that in turn will favor the social dimension of the individual and strengthen the human sense of fullness of life (Wronka-Pospiech, 2013, p. 133).

\section{References}

1. Bartlett, C.A., Ghoshal, S. (1989). Managing Across Borders: The Transnational Solution. Harvard Business School Press.

2. Bartlett, C.A., Ghoshal, S. (1989). Tap Your Subsidiaries for Global Reach. Harvard Business Review, 64, 6.

3. Boreham, N.C. (1999). Knowledge Management in the European Chemical and Internet Industries. University of Manchester.

4. Borkowska, S., Bohdziewicz, P. (1988). Manager at the beginning of the 21st century. University of Humanities and Economics in Łódź.

5. Budnikowski, A. (2003). International economic relations. Warsaw: PWE.

6. Building the new leader. Leadership 2030, 2014 Hay Group. 
7. Cognitive Science and Legal Philosophy (2014). In: M. Zirk-Sadowski, B. Wojciechowski, T. Bekrycht, (eds.), External and internal integration of legal sciences. Łódź.

8. Damon, E. (2010). What is DevOps? dev2ops.org, 11.05.2019.

9. Data Scientist, The Sexiest Job of the 21st Centur. Harvard Business Review, Oct. 2012.

10. Drucker, P.F. (1993). Post-capitalist society. Warsaw: PWN.

11. Edvinsson, L., Malone, M.S. (2001). Intellectual capital. Warsaw: PWN.

12. Gupta, A.K. (2007). Industrial Automation and Robotics. Laxmi Publications (P) Ltd., University Science Press.

13. http://ec.europa.eu/policies/culture_education_youth_en.htm, 12.11.2019.

14. Kaczmarczyk, I. (2018). Development of automation over the centuries.

15. Knowledge management in a learning society (2000). OECD, Ministry of Economy Economic Strategy Department.

16. Kubik, K. (2012). Contemporary enterprises in the face of global competition challenges. Scientific Notebooks of the University of Natural Sciences and Humanities in Siedlce, 92, Series: Administration and Management. Siedlce.

17. Lewandowski, P. (2018). How technology changes the nature of work. Poland against the background of the EU. Warsaw: Institute of Structural Studies.

18. Marszowski, R. (2017). Demand for qualified staff on the labour market of Chorzów. Condition and perspectives. Katowice: GIG, Chorzów: PUP.

19. Matusiak, B., Kuciński, J., Gryzik, A. (ed.) (2009). Foresight of the staff of the modern economy. Warsaw.

20. Naisbitt, J., Aburdene, P. (1985). Reinventing the Corporation Your Job and Your Company for the New Information Society. New York: A. Warner Book.

21. National Active Youth Program. Project of 16 September 2013.

22. Nonaka, I. (1991). The Knowledge Creating Company. Harvard Business Review.

23. Pawlak, M. (2007). Automation of industrial processes. Scientific Works of the Institute of Machines, Drives and Electrical Measurements at the Wrockaw University of Technology, 60.

24. Regional Innovation Strategy of the Ślaskie Voivodeship for the years 2013-2020 (2012). Katowice.

25. Responsible Development Strategy until 2020 with a perspective until 2030 (2017). Warsaw.

26. Robots take over people's work. There are more and more of them in Poland, http://finansecodnia.pl/aktualnosci/15100/Robots-takeover-jobs-people-in-Poland-istheir-ever-more 23.05.2019.

27. Simon, H. (1995). Brainpower, quotation for "World Management". Infoglob, 1.

28. Szczepanik, E., Arendt, Ł. (2007). Investments in human capital in the enterprise development strategy. In: E. Kryńska (ed.), Human capital in small and medium enterprises 
- adaptations to information technologies. Results of empirical research. Warsaw: Institute of Labour and Social Affairs.

29. Understanding European Union Policy - Digital Agenda for Europe (2014). Brussels: European Commission Directorate-General for Social Communication Information for Citizens.

30. Włoch, R. Active + Future of the Labour Market 2017. Report based on a study conducted by DELab UW commissioned by Gumtree Polska as part of the Gumtree.pl Start to Career program.

31. Wronka-Pospiech, M. (2015). Social innovations - concepts and meaning. Economic Studies, Scientific Notebooks of the University of Economics in Katowice, 2012. 